\title{
Importance of empathy level and communication skills of intensive care unit physicians in kidney transplantation
}

\author{
Murat OZTURK'1, Hakan DEMIRCI ${ }^{2}$, Atilla SATIR ${ }^{1}$, Emre YALCINTAS ${ }^{3}$
}

${ }^{1}$ Department of Urology, University of Health Sciences Turkey Bursa Yuksek Ihtisas Training and Research Hospital, Bursa, TURKEY

${ }^{2}$ Department of Family Medicine, University of Health Sciences Turkey Bursa Yuksek Ihtisas Training and Research Hospital, Bursa, TURKEY

Mutareke Family Health Center, Bursa, TURKEY

\begin{abstract}
Aim: The aim of this study was to analyze the correlation between empathy levels of Intensive Care Unit (ICU) physicians and rates of organ donation from cadavers.

Methods: This study was performed with ICU physicians who had been working in intensive care units in 13 hospitals in 6 provinces of Turkey for at least one year. The Jefferson Scale of Empathy healthcare professional version was used in evaluation of empathy status of the ICU physicians. Questionnaires were sent to the ICU physicians by e-mail and forms completed by those who accepted to participate in the study were received by e-mail.

Results: In this study, we found that there was a significant positive correlation between donor declaration and empathy scores of the ICU physicians. A direct significant correlation was obtained between donor declaration and empathy score and age and professional experience. Increase in shift numbers of the ICU physicians, contrary to age and professional experience, caused a decrease in donor declarations.

Conclusions: Organ donation rates could be increased by decreasing the shift load of ICU physicians. Training of younger and less experienced ICU physicians in empathy could ameliorate donor declarations.
\end{abstract}

Keywords: Empathy, organ donation, intensive care units

Corresponding Author: Murat OZTURK muratozturkdr@hotmail.com

Received: March 28, 2021; Accepted:April 5, 2021; Published Online: April 21, 2021

Cite this article as: Ozturk, M., Demirci, H., Satir, A. \& Yalcintas, E. (2021). Importance of empathy level and communication skills of intensive care unit physicians in kidney transplantation. European journal of Human Health $1(1), 14-24$. 



\section{Introduction}

The source for organ transplantations can be either aliving donor or a cadaver. The first successful kidney transplantation in the modern sense was carried out by Dr. Joseph Murray et al. in Boston in 1954 on a patient with renal impairment with kidney donation from his identical twin.The first successful kidney transplantation from a cadaver was performed by Dr. Hume and Dr. Murray in $1962(1,2)$. There was a considerable decrease in organ rejection with the discovery of azathioprine in 1963 andthe development of immunosuppressant drugs,leading to the ability to use cadaver organs.In addition, transplantation success rates have been increasing thanks to antimicrobial drugs, developing surgical techniques andameliorations in organ transplantation organizations. While the rate of cadaver donors is around $80 \%$ in European countries, particularly in Spain, this rate is around $20 \%$ in Turkey $(3,4)$. Among the reasons for this situation, the outstanding reasons are: thehealthcare system, previous experience, intensive care process, beliefs-traditions, opinion of the individual about organ transplantation, recognition of cerebral death, communication with the healthcare team and the media.

The healthcare system is one of the important factors affecting a family's organ donation decision, even if not directly. It is indicated that organ donation rates are lower in societies where the health care system does not work properly and where the community does not rely on the system (5). Experiences of families with organ donation also have an effecton the decision process. Having a relative waiting for organ donation is effective in building a positive attitude toward organ donation $(6,7)$. Although it is suggested in some studies that religious beliefs do not have an effect on organ donation, organ donation rates in Islamic countries are reported to be lower than western countries (8-10). Family members can give the organ donation decision more easily when they are convinced that they received satisfactory medical treatment and care in the intensive care process andif they were informed accurately at the right time about the process $(11,12)$.

One of the most important roles in organ donation falls to intensive care unit (ICU) physicians. Good and efficient communication, as in all circumstances, positively affects the process, while a contrary status decision of the family members can be negative $(5,11$ 13). Empathy between the physician and the patient increases the satisfaction of the patient and the patient's relatives (14). Ability of the physician to develop empathy with his/her patient is associated with his/her education and past experiences.

The fact that empathy skills of nurses providing care to patients in the intensive care process are effective in convincing patient relatives about organ donation was shown in a previous research study (15). The effect of other members of the transplantation team concerning empathy is not yet known. The aim of this study was to analyze the correlation between empathy levels of ICU physicians and rates of organ donation from cadavers.

\section{Methods}

The study was conducted with ICU physicians working in intensive care units in 13 hospitals in 6 provinces of Turkey for at least one year. Ethical approval was obtained from the hospital's ethics committee. The research was conducted in conformity with the Helsinki declaration. Questionnaires were sent to the ICU physicians by e-mail and forms completed by volunteers were received by e-mail. While 220 ICU physicians were in charge in the intensive care units of the related hospitals in the study period, 183 
completed forms were received by the researchers. Response rate for the study was calculated as $83.18 \%$. The ICU physicians were asked about their age, gender, professional experience, period of time working in the related intensive care unit and monthly shift numbers in the socio-demographic data form which was prepared for the study. In addition to this, they were asked the number of brain deaths occurred in their shifts and also the number of these who were accepted to be a cadaver donor.

Healthcare professional version of The Jefferson Scale of Empathy (JSE) was used in evaluation of empathy status of the ICU physicians. JSE is composed of 20 questions and three sub-titles. Assessments were made from the total score. The Turkish translation of the JSE was received from Jefferson University, which holds the copyright of the scale.

\section{Statistical Analysis}

Shapiro Wilk test was used to analyze compatibility of variables to normal distribution. In case of normal distribution, total score of JSE was expressed with mean, standard deviation, minimum and maximum values, and in case of abnormal distribution it was expressed with median, minimum and maximum values with the donor declaration variable. Reliability of the JSE scale was assessed using item-total correlation and Cronbach a coefficient. Correlations between total score of JSE, age, donor declaration, years spent in the profession and shift number variables were analyzed with correlation analysis, and Spearman correlation coefficient was also calculated. Comparisons of donor declaration number and total JSE score among groups were performed using Mann Whitney $\mathrm{U}$ test, Independent samples $\mathrm{t}$ test and Kruskal Wallis test. In case of general significance following Kruskal Wallis test, sub-group analysis wasdone with Conovor-Inman test. Analyses were done using the SPSS program (IBM Corp. Released
2016. IBM SPSS Statisticsfor Windows, Version 24.0. Armonk, NY: IBM Corp.) and in the analysis significance level was taken as $\mathrm{a}=0.05$.

\section{Results}

\section{Item Analysis, Reliability}

Internal consistency of the JSE was analyzed using an item-total score correlation and Cronbach a coefficient and results are given in Table1. The Cronbach a coefficient was $a=0.82$ for the JSE in general. When Cronbach a coefficient is considered, it is seen that JSE is a good tool for measurement in terms of internal consistency. When reliability coefficients of sub-scales were analyzed, the Cronbach a value was $a=0.85$ for the perspective taking sub-scale, $a=0.60$ for the compassionate sub-scale and $a=0.54$ for the standing in the patient's shoes sub-scale. Questions $1,3,6,7,8$, $11,12,14,18$ and 19 were reversely scored in the JSE scoring algorithm and answers given to the related questions in our study were re-coded andtotal and sub-scale scores were calculated using converted scores of the related questions.Item-total score correlation was performed to determine the representation power of the scale items. It was found that correlation coefficients between scores of the remaining 20 questions of the scale and total scale score ranged between $r_{s}=0.29-0.66$ and this was statistically significant $(p<0.001)$. In the analysis of correlations between each sub-scale score and JSE total scores, correlation coefficients varied between $r_{s}=0.62-0.83$ and this was statistically significant $(p<0.001)$.Sub-scales of JSE were found to be interrelated. Validity of the JSE was shown by Ozturk et al (15). 
Table1. Reliability levels of Jefferson Scale of Empathy sub-scales

\begin{tabular}{|l|l|l|l|}
\hline Scale and Sub-scales & Cronbach $\alpha$ & $\begin{array}{l}\text { Total scale and sub-scale } \\
\text { correlations }\left(r_{s}\right)\end{array}$ & Mean \pm Sd. Deviation \\
\hline Jefferson Scale of Empathy & 0.82 & - & $99.46 \pm 15.19$ \\
\hline Perspective taking & 0.85 & $0.83^{*}$ & $53.38 \pm 9.41$ \\
(Item 2, 4, 5, 9, 10, 13, 15, 16, 17, 20) & 0.60 & $0.78^{*}$ & $35.88 \pm 7.16$ \\
\hline Compassionate care & & & \\
$($ Item $1,7,8,11,12,14,18,19)$ & 0.54 & $0.62^{*}$ & $10.20 \pm 2.51$ \\
\hline Standing in the patient's shoes & & & \\
\hline (Item 3, 6) & & & \\
\hline
\end{tabular}

$r_{s}:$ Spearman correlation coefficient; *:significant at $p<0.001 /$ evel

Distributions, percentiles and descriptive statistics for scores of JSE for 183 ICU physicians are given in Table 2.

Table 2. Distributions, Percentiles and Descriptive Statistics for Scores on Empathy of the Physicians

\begin{tabular}{|c|c|c|c|}
\hline Score Variable & Frequency & Cumulative Frequency & Cumulative \% \\
\hline $52-55$ & 1 & 1 & $0.50 \%$ \\
\hline $56-60$ & 1 & 2 & $1.10 \%$ \\
\hline $61-65$ & 2 & 4 & $2.20 \%$ \\
\hline $66-70$ & 2 & 6 & $3.30 \%$ \\
\hline 71-75 & 4 & 10 & $5.50 \%$ \\
\hline $76-80$ & 11 & 21 & $11.50 \%$ \\
\hline $81-85$ & 11 & 32 & $17.50 \%$ \\
\hline $86-90$ & 16 & 48 & $26.20 \%$ \\
\hline $91-95$ & 17 & 65 & $35.50 \%$ \\
\hline $96-100$ & 24 & 89 & $48.60 \%$ \\
\hline
\end{tabular}


Table 2. Distributions, Percentiles and Descriptive Statistics for Scores on Empathy of the Physicians (Continued)

\begin{tabular}{|c|c|c|c|}
\hline $101-105$ & 35 & 124 & $67.80 \%$ \\
\hline $106-110$ & 16 & 140 & $76.50 \%$ \\
\hline $111-115$ & 15 & 155 & $84.70 \%$ \\
\hline $116-120$ & 12 & 167 & $91.30 \%$ \\
\hline $121-125$ & 10 & 177 & $96.70 \%$ \\
\hline $126-130$ & 4 & 181 & $98.90 \%$ \\
\hline $131-135$ & 2 & 183 & $100 \%$ \\
\hline Mean & 99.46 & & \\
\hline Standard Deviation & 15.19 & & \\
\hline \multicolumn{4}{|l|}{ Percentile } \\
\hline 25 th & 90 & & \\
\hline $50^{\text {th }}$ (median) & 101 & & \\
\hline 75th & 109 & & \\
\hline Minimum-Maximum & $52-134$ & & \\
\hline
\end{tabular}

General characteristics of the participants and donor declarations by hospitals are given in Table 3 . According to this, the mean age of the participants was calculated as $37.80 \pm 8.17$. There were 78 male and 105 female participants. Mean professional experience of the ICU physicians was six years and they were on duty four times a month on average.

Table 3. General characteristics of the participants and donor declarations by hospitals

\begin{tabular}{|l|l|}
\hline Variable & $\mathrm{n}=183$ \\
\hline Age (year) & $37.80 \pm 8.17(25: 58)$ \\
\hline Sex(Male/Female) & $78(42.60 \%) / 105(57.40 \%)$ \\
\hline Professional experience (year) & $6(1: 25)$ \\
\hline Shift & $4(0: 11)$ \\
\hline
\end{tabular}


Table 3. General characteristics of the participants and donor declarations by hospitals (Continued)

\begin{tabular}{|c|c|}
\hline Hospit & \\
\hline 1 & $18(9.80 \%)$ \\
\hline 2 & $29(15.80 \%)$ \\
\hline 3 & $6(3.30 \%)$ \\
\hline 4 & $6(3.30 \%)$ \\
\hline 5 & $2(1.10 \%)$ \\
\hline 6 & $28(15.30 \%)$ \\
\hline 7 & $14(7.70 \%)$ \\
\hline 8 & $17(9.30 \%)$ \\
\hline 9 & $9(4.90 \%)$ \\
\hline 10 & $15(8.20 \%)$ \\
\hline 11 & $16(8.70 \%)$ \\
\hline 12 & $15(8.20 \%)$ \\
\hline 13 & $8(4.40 \%)$ \\
\hline \multicolumn{2}{|c|}{ Donor Declaration } \\
\hline None & $61(33.30 \%)$ \\
\hline 1 & $48(26.20 \%)$ \\
\hline 2 & $31(16.90 \%)$ \\
\hline 3 & $20(10.90 \%)$ \\
\hline 4 & $17(9.30 \%)$ \\
\hline 5 & $3(1.60 \%)$ \\
\hline 6 & $1(0.50 \%)$ \\
\hline 8 & $2(1.10 \%)$ \\
\hline
\end{tabular}

Data are presented as mean \pm st. deviation (min.: max.), median (min.: max.) or $n$ (\%). 
General characteristics and empathy status of the participants are shown in Table4. A positively significant correlation was found between empathy score and age. An increase is determined in empathy score with an increase in age. A positively significant correlation was detected between professional experience and empathy score. Empathy score increased as professional experience increased. A positively significant correlation was detected between donor declaration rate and empathy score. An increase was seen in empathy score with an increase in donor declaration. It was detected that the mean empathy score was higher for women compared to men. There was a difference among hospitals in terms of empathy score. In our study we found a direct and significant correlation between total empathy score and donor finding rate $\left(r_{s}=0.21 ; p=0.007\right)$. An increase in empathy score led to an increase in the donor finding rate.

Table 4. General characteristics of the participants and their empathy status

\begin{tabular}{|c|c|c|}
\hline & \multicolumn{2}{|l|}{ Total Empathy Score } \\
\hline & $r_{s}$ & $\mathrm{p}$ \\
\hline Age (year) & 0.26 & $<0.001$ \\
\hline Professional Experience & 0.27 & $<0.001$ \\
\hline Shift & -0.12 & 0.110 \\
\hline Donor Declaration & 0.27 & $<0.001$ \\
\hline Gender & \multicolumn{2}{|l|}{ Total Empathy Score } \\
\hline Male $(n=78)$ & \multicolumn{2}{|l|}{$96.60 \pm 15.42(52: 132)$} \\
\hline Female $(n=105)$ & \multicolumn{2}{|l|}{$101.58 \pm 14.73(64: 134)$} \\
\hline$p$-value & \multicolumn{2}{|l|}{$0.028^{\mathrm{a}}$} \\
\hline Hospital & \multicolumn{2}{|l|}{ Total Empathy Score } \\
\hline $4(n=6)$ & \multicolumn{2}{|l|}{ 115(99:132) } \\
\hline $1(n=18)$ & \multicolumn{2}{|l|}{$107.50(80: 134)$} \\
\hline $3(n=6)$ & \multicolumn{2}{|l|}{ 106.50(104:128) } \\
\hline $7(n=14)$ & \multicolumn{2}{|l|}{$106.50(86: 130)$} \\
\hline $9(n=9)$ & \multicolumn{2}{|l|}{$100(76: 129)$} \\
\hline
\end{tabular}


Table 4. General characteristics of the participants and their empathy status (Contunued)

\begin{tabular}{|l|l|}
\hline $10(n=15)$ & $98(76: 109)$ \\
\hline $13(n=8)$ & $97.50(93: 105)$ \\
\hline $2(n=29)$ & $97(60: 124)$ \\
\hline $8(n=17)$ & $96(66: 112)$ \\
\hline $12(n=15)$ & $96(69: 123)$ \\
\hline $11(n=16)$ & $95.50(77: 118)$ \\
\hline $5(n=2)^{*}$ & $94.50(88: 101)$ \\
\hline $6(n=28)$ & $92.50(52: 124)$ \\
\hline$p$-value & $0.013^{\mathrm{b}}$ \\
\hline
\end{tabular}

Data are presented as mean \pm st. deviation (min.: max.) or median (min.: max.) a: Independent samples $t$ test, $b:$ Kruskal Wallis test, $r_{s}:$ Spearman correlation coefficient *: Hospital no: 5 was excluded from the analysis as its unit number $(n=2)$ was not sufficient for statistical comparison.

Factors affecting donor declaration are seen in Table5. A direct significant correlation was obtained between donor declaration and age and professional experience (respectively, $r_{s}=0.24, p=0.001$ and $r_{s}=0.22, p=0.002$ ). Increase in age and professional experience caused an increase in number of donor declarations. Despite this, a reverse significant correlation was detected between donor declaration and shift number $\left(r_{s}=-0.18, p=0.017\right)$. Increase in shift number, contrary to age and professional experience, caused a decrease in donor declarations. There was no difference between gender groups in terms of donor declaration number.

Table 5: Factors affecting donor declaration

\begin{tabular}{|c|c|c|}
\hline \multirow{2}{*}{} & \multicolumn{2}{|c|}{ Donor Declaration } \\
\cline { 2 - 4 } & $r_{\mathrm{s}}$ & 0.001 \\
\hline Age (years) & 0.24 & 0.002 \\
\hline Professional experience & 0.22 & 0.017 \\
\hline Shift & -0.18 & Donor Declaration \\
\hline Gender & & $1(0: 5)$ \\
\hline Male $(n=78)$ & & $1(0: 8)$ \\
\hline$p$-value & & $0.059^{c}$ \\
\hline
\end{tabular}




\section{Discussion}

In this study, we found that there was a significant positivecorrelation between donor declaration and empathy scores of the ICU physicians. A direct significant correlation was obtained between donor declaration and empathy scoreand age and professional experience. Increase in shift numbers of the ICU physicians, contrary to age and professional experience, caused a decrease in donor declarations.Mean empathy score of female ICU physicians was higher than male ICU physicians.A direct significant correlation was found between empathy score and donor finding rate among hospitals.

The mean JSE score of the participants was $99.46 \pm 15.19$ in this study analyzing a correlation between empathy level of ICU physicians andorgan finding from cadavers. When the highest score of the scale is considered as 140, empathy level can be assumed as 'moderate'. The mean score in our study was lower compared to the mean scores reported in the study of DiLillo et al. in Italy and the study of Hojat et al. with American physicians $(16,17)$.

An increase was detected in empathy score with age and professional experience of the ICU physicians and a statistical increase in donor declaration number. In the studies performed on empathy levels of medical students, a decrease was detected with advanced classes and passing years $(18,19)$. Loss of idealism, over-activity and decrease in role models that can support empathy are considered responsible for this decrease.However, in this current study, wefound that empathy in ICU physicianswas affected positively with passing years. This result must be further studied in future research.

A reverse correlation was detected between donor declaration and increase in number of shifts.A decrease in donor declaration of ICU physicians can be possible due to a decrease in empathy and idealism following fatigue caused by over-activity. For this reason, work motivation of the ICU physicians can be increased by proper arrangement of their working hours. In this waydonor declaration rates could be increased.In a study conducted in USA, a correlation was found between exhaustion and empathy and it was shown that exhaustion was more important than depression in regression of empathy (20). Excessive shifts may have triggered exhaustion and a decrease in empathy.

Emotional exhaustion and desensitization decrease and personal success increases as empathic tendency increases (21). The contrary is also true. Empathic approach decreases as exhaustion increases.According to a study on exhaustion, exhaustion is more prevalent in young and less experienced employees (22).Variables related to the organization have an important role in exhaustion occurrence in employees.A low number of employees increases work load.Long working hours with deep interaction with the patients and shift pattern can both be exhausting.Working in shifts disarranges the daily order, causes sleeplessness and can be physically compelling $(23,24)$.

In this study, the mean score of empathy was higher in female ICU physicians than males. In the literaturethere is no theory that implicitly explains the effect of gender on empathy. On the contrary, there are studies showing that empathy level does not differentiate with gender $(25,26)$.Although empathy differentiated with gender, organ donation rates were not associated with gender.

Empathy score averages showed significant differences among hospitals. Our study was conducted withICU physicians working in 13 hospitals in 6 provinces of Turkey.Hospitals with high empathy scores also had 
high rates of donor declaration rates. Empathy positively affects organ donation rates cumulatively in hospitalsas well as individually.

As this was the first study to finda correlation between empathy levels of ICU physicians and their success in organ finding, it was not possible to compare the results with other similar research. In the study of Ozturk et al. (15) on empathy levels of intensive care nurses and their donor finding rates, a positive and significant correlation was found between donor declaration and empathy score. In the study in question, no correlation was found between donor declaration rate and professional experience, age and number of shifts (15). In another study, the association between empathy levels in organ transplant coordinators and their success rates of organ donation was examined (27). But, no variable related to organ transplant coordinators was associated with the number of organ donations. The possible reasons suggested by the authors were shortterm and late communication by the coordinators. In the present study, the reverse correlation between shift numbers of ICU physicians and their donor declaration rates can arise from the fact that in Turkey the working hours usually continue before and after their shifts.Exhaustion can increase and donor declaration rate can decrease due to empathy decrease because of working hours that can lengthen up to 24 hours in total. As nurses generally work only in shifts, it is possible that no correlation was detected between their shift numbers and donor declaration rates.

\section{Limitations}

This study was limited to Turkey and included ICU physicians working in 13 hospitals in 6 provinces, where numerous donor declarations occur. As it was a national scaled study, it is possible that different results could be achieved with similar studies in other countries. Prospective and larger scale research studies are necessary. We completed the study via email. This could also be a limitation of our study.

\section{Conclusions}

In conclusion, the empathy status ofICU physicianshas an effect on donor declaration. While age and professional experience of ICU physicians positively affects their donor finding,an increase in their number of shifts has a negative effect on donor finding.For this reason, organ donation rates could be increased by decreasing the working hours and shift load of ICU physicians. Training of younger and less experienced ICU physicians in empathy could ameliorate donor declarations. In this way, individuals waiting for organs could be treated more efficiently and at the right time.

\section{Conflict of interest}

The authors declare that there is no conflict of interest. 


\section{References}

1-Tilney, N. L. (2003). Transplant: from myth to reality. Yale University Press.

2-Merrill, J. P.,Murray, J. E., Harrison, J. H., \&Guild, W. R. (1956). Successful homo transplantation of the human kidney between identical twins. Journal of the American Medical Association, 160(4), 277-282.

3-Edirne, T. (2004). Türkiye'de organ ve doku nakli uygulamaları: Sonuçları ve Strateji önerileri. Turkiye Klinikleri Journal of Medical Sciences, 24(3), 261-266.

4-Yücetin, L., Keçecioğlu, N., \& Ersoy, F. F. (2003). Türkiye'de organ bağışı ve nakline bir bakış. Diyaliz Transplantasyon ve Yanık, 14(2), 115-118.

5-Donaldson, T. A. (2003). The role of the transplant coordinator. Transplantation nursing secrets. Philadelphia, PA: Hanley\&Belfus, 20-4.

6-Santiago, C. (1997, February). Family and personal consent to donation. In Transplantation proceedings (Vol. 29, No. 1-2, pp. 1625-1628). Elsevier.

7-Burroughs, T. E., Hong, B. A., Kappel, D. F., \&Freedman, B. K. (1998). Thestability of family decisions to consent or refuse organ donation: would you do it again. Psychosomatic medicine, 60(2), 156-162.

8-Horoz, A., Harmanci, A. K., \& Yavuz, H. (2011). Muslim ecclesiastics as the key role to organ donation: A survey study from Istanbul. Organs, Tissues \& Cells, 14(1), 4345.

9-Al-Mousawi, M.,Hamed, T., \& Al-Matouk, H. (1997, December). Views of Muslim scholars on organ donation and brain death. In Transplantation proceedings(Vol. 29, No. 8, p. 3217).

10-El-Shahat, Y. I. M. (1999). Islamic viewpoint of organ transplantation. In Transplantation Proceedings (Vol. 8, No. 31, pp. 3271-3274).

11-Coyle, M. A. (2000). Meeting the needs of thefamily: the role of the specialist nurse in the management of brain death. Intensive and Critical Care Nursing, 16(1), 45-50.

12-Meyer, K., Bjørk, I. T., \&Eide, H. (2012). Intensivecare nurses' perceptions of their Professional competence in the organ donor process: a nationals urvey. Journal of Advanced Nursing, 68(1), 104-115.

13-Villar, C. R. (2007). Family Approach for organ donation. Manyalich $M$.

14-Beckman, H. B.,\&Frankel, R. M. (1984). The effect of physician behavior on the collection of data. Annals of Internal medicine, 101(5), 692-696.

15-Ozturk, M.\& Demirci, H. (2018). Turkish validation of the Jefferson scale of empathy for nurses seeking kidney donations in intensivecare units. The Aging Male, 1-7.
16-Hojat M, SalvatoreMangione, Thomas J. Nasca, Mitchell J. M. Cohen, Joseph S. Gonnella, James B. Erdmann, et al. The Jefferson Scale of Physician Empathy: Development and Preliminary Psychometric Data. Educ. PsycholMeas 2001;61:349-65.

17-DiLillo, M.,Cicchetti, A., Scalzo, A. L., Taroni, F., \&Hojat, M. (2009). The Jefferson Scale of PhysicianEmpathy: preliminary psychometrics and group comparisons in Italian physicians. AcademicMedicine, 84(9), 1198-1202.

18-Hojat, M.,Mangione, S., Nasca, T. J., Rattner, S., Erdmann, J. B., Gonnella, J. S., \&Magee, M. (2004). An empiricalstudy of decline in empathy in medicalschool. Medicaleducation, 38(9), 934-941.

19-Wen, D.,Ma, X., Li, H., Liu, Z., Xian, B., \&Liu, Y. (2013). Empathy in Chinese medical students: psychometric characteristics and differences by gender and year of medical education. BMC medical education, 13(1), 130.

20-Thomas, M. R. Dyrbye, L. N.,Huntington, J. L., Lawson, K. L., Novotny, P. J., Sloan, J. A., \&Shanafelt, T. D. (2007). How do distress and well-being relateto medical student empathy? A multicenter study. Journal of general internal medicine, 22(2), 177-183.

21-Köksal, H. (2009). Hemşirelerin empatik eğilim ve tükenmişslik düzeyleri arasındaki ilişkinin belirlenmesi (Doctoraldissertation, DEÜ Sağlık Bilimleri Enstitüsü).

22-Brewer, E. W.,\&Shapard, L. (2004). Employeeburnout: A meta-analysis of the relationship between age or years of experience. Human resource development review, 3(2), 102-123.

23-Lee, H.,Song, R., Cho, Y. S., Lee, G. Z., \&Daly, B. (2003). A comprehensive model for predicting burnout in Koreannurses. Journal of Advanced Nursing, 44(5), 534545.

24-Üstün, B. (1995). Hemşirelerin atılganlık ve tükenmişlik düzeyleri. Yayınlanmamış Doktora Tezi, Hacettepe Üniversitesi Sağlık Bilim/eri Enstitüsü, Ankara.

25-McKenna L, Boyle M, Brown T, Williams B, MolloyA, Lewis $B$, et al. Levels of empathy in undergraduate nursing students. Int J NursPract 2012;18:246-51.

26-Yucel $H$, Acar G.Levels of empathy among undergraduate physiotherapy students: A cross-sectional study at two universities in Istanbul. Pak J MedSci 2016;32:85-90.

27- Öztürk, M., \& Demirci, H. Importance of Empathy in Transplant Coordinators during Organ Donation from Cadavers. Turk J Nephrol 29(2): 129-33. 